\title{
O DIREITO FUNDAMENTAL A UM MEIO AMBIENTE SADIO E A NECESSÁRIA SUSTENTABILIDADE
}

\author{
Carina da Cunha Alvez ${ }^{1}$ \\ Jucelma de Cássia Tolotti Mainardi ${ }^{2}$ \\ Wagner Augusto Hundertmarck Pompéo ${ }^{3}$ \\ Carlos Djalma Silva da Rosa ${ }^{4}$
}

\begin{abstract}
RESUMO: O direito fundamental a um meio ambiente sadio passou à categoria de direito fundamental propriamente dito a partir da edição da Constituição Federal de 1988, pois foi especificamente garantido no corpo da Carta Magna, em seu artigo 225 e seus parágrafos. Ocorre que para se determinar o âmbito de proteção deste novo direito fundamental, tem-se que estabelecer os parâmetros conceituais do meio ambiente e, ter claro que a acepção envolve o ambiente natural, o artificial e o cultural. Para a efetividade deste direito é necessário um primeiro passo no sentido de se implementar a compatibilização entre a preservação do meio ambiente e a continuidade do desenvolvimento/crescimento econômico e tecnológico, ou seja, mister consubstanciar o desenvolvimento sustentável - que por si só não exterminará os danos ambientais, mas é fator positivo na tutela específica.
\end{abstract}

PALAVRAS-CHAVE: Direito; Fundamental; Meio-ambiente; Desenvolvimento.

ABSTRACT: The primordial right to a healthy environment only moved into the stated fundamental right category in the 1988 edition of the Federal Constitution, where it was specifically warranted in the "Carta Magna" corpus, in clause 225 and its paragraphs. It occurs that, to establish the extent of protection of this new fundamental right, environment conceptual parameters, which involve the natural, artificial and cultural environment, must be established. For this right to be effective, it is necessary a first step towards the improvement of compatibility between the environment conservation and the continuity of economical and technological development, that is, to fortify the sustainable development- that itself is not going to exterminate the environment damages but it is a positive factor in this specific matter.

KEY-WORDS: Right; Fundamental; Environment;Development.

\section{CONSIDERAÇÕES INICIAIS}

O direito fundamental a um meio ambiente sadio se constitui em um direito material e, para tanto, em determinadas situações faz-se mister a utilização de instrumentos que viabilizem a efetividade de tal prerrogativa.

Importante evidenciar que "o meio ambiente é a interação do conjunto de elementos naturais, artificiais e culturais que propiciem o desenvolvimento equilibrado da vida em todas as suas formas". ${ }^{5}$ Ocorre que a qualidade do meio ambiente influencia diretamente a qualidade de vida, sendo que as normas de proteção ambiental surgiram

\footnotetext{
${ }^{1}$ Advogada militante em Santa Maria/RS. Professora do Curso de Direito e de Administração da Faculdade Metodista de Santa Maria.Mestra em Direito pela Universidade de Santa Cruz do Sul.

${ }^{2}$ Acadêmica do $7^{\circ}$ Semestre do Curso de Direito da Faculdade Metodista de Santa Maria.

${ }^{3}$ Acadêmico do $7^{\circ}$ Semestre doCurso de Direito da Faculdade Metodista de Santa Maria.

${ }^{4}$ Acadêmico do $4^{\circ}$ Semestre do Curso de Direito da Universidade Federal de Santa Maria.

${ }^{5}$ SILVA, José Afonso da. Direito Ambiental Constitucional. São Paulo: Malheiros, 2000, p - 20.

ISSN 1981-3694

(C) 2008. Departamento de Direito da UFSM. Todos os direitos reservados.
} 
quando a degradação do meio ambiente começou a ameaçar a preservação da espécie humana.

A proteção ambiental visa à manutenção do equilíbrio ecológico, de modo a tutelar a qualidade do meio ambiente em razão da qualidade de vida, aparecendo esta última como forma de direito fundamental da pessoa humana - nova necessidade social, pela acepção da preservação do meio ambiente como tutela da vida. Assim, é o direito à vida que deve orientar as formas de tutela do meio ambiente; pois é através da tutela da qualidade do meio ambiente que se protege efetivamente a qualidade de vida. Consoante Paulo de Bessa Antunes, "a construção prática do Direito Ambiental demonstra que este, em grande medida, é fruto da luta dos cidadãos por uma nova forma e qualidade de vida."6

Um fator de suma relevância dentro dos aspectos que envolvem a proteção do meio ambiente é que, na sociedade atual, é impossível frear o crescimento econômico; mas o mesmo deve orientar-se de forma a não destruir elementos naturais e culturais. $\mathrm{O}$ desenvolvimento deve ocorrer de maneira sustentada, ou seja, mediante a exploração equilibrada dos recursos naturais, tendo como limite a satisfação das necessidades das gerações presentes e futuras. "O desenvolvimento sustentável é aquele que atende as necessidades do presente sem comprometer a possibilidade das gerações futuras atenderem as suas próprias necessidades".7

Cumpre evidenciar que para haver a efetividade do direito fundamental a um meio ambiente sadio vários fatores devem ser implementados em busca da sustentabilidade necessária, do que é mister a compreensão do conceito de meio ambiente, consciência ambiental, caracterização do direito ambiental como um direito fundamental, aspectos relacionados com a qualidade do meio ambiente, qualidade de vida e desenvolvimento econômico.

\section{Conceito de meio ambiente}

Inicialmente cumpre destacar que para a compreensão do conceito de meio ambiente faz-se mister a assimilação de que meio ambiente é um conceito ainda em

\footnotetext{
${ }^{6}$ ANTUNES, Paulo de Bessa. Direito Ambiental. Rio de Janeiro: Lumen Juris, 2001, p - 17.

${ }^{7}$ SÉGUIN, Elida e CARRERA, Francisco. Planeta Terra Uma Abordagem de Direito Ambiental. Rio de Janeiro: Lumen Juris, 2001, p - 119.
} 
formação e que tem passado por modificações em virtude dos avanços ocorridos e das alterações advindas na modernidade.

Dessa forma, tem-se que "o meio ambiente é, assim, a interação do conjunto de elementos naturais, artificiais e culturais que propiciem o desenvolvimento equilibrado da vida em todas as suas formas". 8

Sabe-se que há tempos atrás a acepção de meio ambiente era estritamente vinculada à natureza e que o ambiente artificial e cultural ficavam a margem das relações existentes.

Ressalta-se, ainda, que em uma visão antropocêntrica, anteriormente adotada, o homem era colocado como centro nas relações existentes com a natureza e, assumia o verdadeiro papel de detentor dos bens naturais "colocados à sua disposição".

Ocorre, entretanto, que pelo avanço da sociedade como um todo, esta visão antropocêntrica passou a ser substituída pela visão holística, na qual o homem interage com o ambiente que o circunda e está contido no próprio conceito de meio ambiente, como bem assevera Édis Milaré “fala-se, atualmente, numa visão holística do meio ambiente, querendo-se com isso significar o caráter abrangente e multidisciplinar que a problemática ambiental necessariamente requer". 9

Existe a necessidade da compreensão de que o homem e o meio ambiente não são conceitos passíveis de divisão, uma vez que o homem é parte integrante do meio.

Importante destacar que:

O tema ambiental extrapola os limites territoriais de um país, pois a Natureza não conhece fronteiras políticas. (...) O reconhecimento da existência de territórios economicamente naturais, ou seja, espaços integrados que não podem ser tratados isoladamente, torna o Meio Ambiente um bem transnacional, patrimônio de todos os seres vivos, das presentes e futuras gerações. $^{10}$

Destaca-se as enunciações de José Rubens Morato Leite, “qualquer que seja o conceito que se adotar, o meio ambiente engloba, sem dúvida, o homem e a natureza, com todos os elementos. Dessa forma, se ocorrer uma danosidade ao meio ambiente,

\footnotetext{
${ }^{8}$ SILVA, José Afonso. Op. Cit. p - 20.

${ }^{9}$ MILARÉ, Édis, Op. Cit. p - 65.

${ }^{10}$ SÉGUIN, Elida e CARRERA, Francisco. Op. Cit. p-30.

(C) 2008. Departamento de Direito da UFSM. Todos os direitos reservados.
} 
esta se estende à coletividade humana, considerando se tratar de um bem difuso interdependente". 11

Ocorre que no tocante à conceituação de meio ambiente tem-se que vislumbrar a definição legal adotada, tanto pela Lei de Política Nacional do Meio Ambiente, quanto pela Constituição Federal.

Primeiramente, a Lei 6.938/81 em seu art. 30 inciso I assim determina: "meio ambiente, o conjunto de condições, leis, influências e interações de ordem física, química e biológica, que permite, abriga e rege a vida em todas as suas formas".

A Constituição Federal estatui em seu art. 225 estatui que "todos têm direito ao meio ambiente ecologicamente equilibrado, bem de uso comum do povo e essencial à sadia qualidade de vida".

Da análise dos textos legais constata-se que "tanto a Lei 6.938/81 quanto a Lei Maior omitem-se sobre a consideração essencial de que o ser humano, considerado como indivíduo ou como coletividade, é parte integrante do mundo natural e, por conseguinte, do meio ambiente". ${ }^{12}$

Assim sendo, dentre os diversos e numerosos conceitos existentes, para que exista a plena compreensão do tema, é mister que se considere o meio ambiente como “ conjunto de elementos físicos-químicos, ecossistemas naturais e sociais em que se insere o Homem, individual e socialmente, num processo de interação que atenda ao desenvolvimento das atividades humanas, à preservação dos recursos naturais e das características essenciais do entorno, dentro de padrões de qualidade definidos". ${ }^{13}$

\section{Consciência ambiental}

É de extrema importância para a efetividade da preservação ambiental que exista uma consciência ecológica no sentido de que o meio ambiente é patrimônio da coletividade, não se podendo dispor dos recursos livremente, pois há interesses mais amplos da coletividade que não devem ser violados; pois do contrário, não será possível permitir que as gerações futuras tenham os mesmos recursos naturais colocados à disposição da presente geração.

\footnotetext{
${ }^{11}$ VARELLA, Marcelo Dias e BORGES, Roxana Cardoso B. O Novo em Direito Ambiental. Belo Horizonte: Del Rey, 1998, p - 53.

${ }^{12}$ MILARÉ, Édis, Op. Cit. p - 66.

${ }^{13}$ COIMBRA, José de Ávila Aguiar. O outro lado do meio ambiente. São Paulo: Cetesb, 1990. p - 29.

(C) 2008. Departamento de Direito da UFSM. Todos os direitos reservados.
} 
Assim, "é possível e obrigatório à sociedade preocupar-se com a preservação da natureza, visto que o benefício de toda a espécie humana o requer". ${ }^{14}$

Importante destacar que a conscientização ambiental passa pela necessária alteração da concepção individualista herdada até então, na qual inexiste formação voltada para o social.

Ocorre que de nada adianta a existência de normas protetivas do meio ambiente, se não existir a sensibilização da coletividade quanto às consequiências advindas da falta de proteção ambiental, pois "só depois que o homem começou a conhecer a interação dos microorganismos existentes no ecossistema é que sua responsabilidade aumentou". 15

Assim sendo, acredita-se que um instrumento adequado para ampliar a conscientização ambiental é através da promoção da educação ambiental, colocando em prática as determinações legais da Lei 9.795/99, pois “a Constituição Brasileira, expressamente, estabelece que é uma obrigação do Estado a promoção da educação ambiental como forma de atuação com vistas à preservação ambiental". ${ }^{16}$

Entende-se que é necessária a revisão das relações que se estabelecem entre homem, mundo natural, sociedade e meio ambiente mediante a ética ambiental, sendo imprescindível a reformulação de determinados paradigmas.

Interessante neste aspecto é a construção de uma conscientização da coletividade, através da sensibilização quanto à necessária preservação ambiental de forma que as gerações futuras possam usufruir dos recursos naturais na mesma proporção que a atual.

\section{4. $O$ direito ambiental como um direito fundamental}

Cumpre estabelecer os parâmetros conceituais do direito ambiental, pois somente assim poder-se-á compreendê-lo como direito fundamental.

$\mathrm{O}$ direito ambiental recebe vários conceitos dos quais destaca-se: " Direito Ambiental é a ciência jurídica que estuda, analisa e discute as questões e os problemas

\footnotetext{
${ }^{14}$ MILARÉ, Édis, Op. Cit. p - 74.

${ }^{15}$ SIRVINSKAS, Luís Paulo. Manual de Direito Ambiental. São Paulo: Saraiva, 2002, p - 3.

${ }^{16}$ ANTUNES, Paulo de Bessa. Op. Cit. p - 175. 
ambientais e sua relação com o ser humano, tendo por finalidade a proteção do meio ambiente e a melhoria das condições de vida no planeta". ${ }^{17}$

Por sua vez Édis Milaré o conceitua como “ complexo de princípios e normas coercitivas reguladoras das atividades humanas que, direta ou indiretamente, possam afetar a sanidade do ambiente em sua dimensão global, visando à sua sustentabilidade para as presentes e futuras gerações". ${ }^{18}$

Destaca-se o caráter inovador das normas do direito ambiental no tocante à preocupação com as gerações futuras, pois ao invés de estabelecer regras e princípios reguladores das relações jurídicas estabelecidas, visa à preservação do meio ambiente para que as próximas gerações continuem a usufruir do patrimônio ambiental.

Ocorre que a elevação do direito ambiental à categoria de direito fundamental emergiu a partir da conferência de Estocolmo ${ }^{19}$, que "elevou o meio ambiente de qualidade ao nível de direito fundamental do ser humano". ${ }^{20}$

A partir da referida conferência "o novo ambientalismo evoluiu para termos que eram politicamente mais aceitáveis, encorajando mais governos nacionais a fazer do meio ambiente uma questão de política". ${ }^{21} \mathrm{E}$, ainda, "da leitura global dos diversos preceitos constitucionais ligados à proteção ambiental, chega-se à conclusão que existe verdadeira consagração de uma política ambiental, como também de um dever jurídico constitucional atribuído ao Estado". 22

Obviamente pelo caráter difuso ${ }^{23}$ deste direito, não se pode individualizar sua realização, que somente é possível se interligado à realidade social. Significando que, "para efetividade deste direito, há necessidade da participação do Estado e da coletividade, em consonância com o preceito constitucional". ${ }^{24}$

Evidencia-se em realidade que o direito fundamental a um meio ambiente sadio nada mais é do que um novo viés de proteção do direito à vida, como assevera Santiago

\footnotetext{
${ }^{17}$ SIRVINSKAS, Luís Paulo. Op. Cit. p - 23.

${ }^{18}$ MILARÉ, Édis, Op. Cit. p - 109.

${ }^{19}$ A conferência de Estocolmo foi o acontecimento isolado que mais influenciou na evolução do movimento ambientalista internacional.

${ }^{20}$ VARELLA, Marcelo Dias e BORGES, Roxana Cardoso B. Op. Cit. p - 64.

${ }^{21}$ MCCORMICK, John. Rumo ao Paraíso. A história do Movimento Ambientalista. Rio de Janeiro: Relume-Dumerá, 1992.

${ }^{22}$ VARELLA, Marcelo Dias e BORGES, Roxana Cardoso B. Op. Cit. p - 64.

${ }^{23}$ Direitos Difusos, segundo Élida Séguin e Francisco Carrera, são aqueles que pertencem a um número indeterminável de pessoas, sem se fixar em uma determinada pessoa ou em um determinado grupo.

${ }^{24}$ VARELLA, Marcelo Dias e BORGES, Roxana Cardoso B. Op. Cit. p - 66.
} 
Anglada Gotor, ao dizer que "encontramo-nos diante de uma nova projeção do direito à vida, pois neste há de incluir-se a manutenção daquelas condições ambientais que são suportes da própria vida, e o ordenamento jurídico, a que compete tutelar o interesse público, há que dar resposta coerente e eficaz a essa nova necessidade social". ${ }^{25}$

Importante destacar que a nova necessidade social que se coloca, quanto ao aspecto de preservação ambiental como instrumento de salvaguarda do direito à vida provém "da luta dos cidadãos por uma nova forma e qualidade de vida" 26

No direito brasileiro, a consagração do direito ambiental como um direito fundamental encontra-se na previsão constitucional do art. 225, enfatizando o caráter do interesse comum dos bens ambientais; bem como no art. $5^{\circ}$ da Constituição Federal que resguarda o direito à vida.

Evidencia-se que a efetividade deste direito fundamental somente é viável como participação da coletividade em conjugação com o Poder Público. Além disso, é mister atuação não restrita aos limites Estaduais, mas sim supranacionais, do contrário não se pode falar em efetividade, como cem assevera José Rubens Morato Leite, “É, de fato, a proclamação de um direito fundamental intergeracional de participação solidária e, como consequiência, extrapola, em seu alcance, o direito nacional de cada estado soberano e atinge o patamar intercomunitário, caracterizando-se como um direito que assiste a toda a humanidade". ${ }^{27}$

$\mathrm{Na}$ acepção de direito fundamental, "a proteção ambiental, abrangendo a preservação da Natureza em todos os seus elementos essenciais à vida humana e à manutenção do equilíbrio ecológico, visa a tutelar a qualidade do meio ambiente em função da qualidade de vida, como uma forma de direito fundamental da pessoa humana". 28

\section{Qualidade do meio ambiente, qualidade de vida e desevolvimento} econômico

Falar em qualidade do meio ambiente envolve o conceito de qualidade de vida, pois somente em um meio ambiente sadio ter-se-á a almejada qualidade de vida, como

\footnotetext{
${ }^{25}$ SILVA, José Afonso. Op. Cit. p - 58.

${ }^{26}$ ANTUNES, Paulo de Bessa. Op. Cit. p - 17

${ }^{27}$ VARELLA, Marcelo Dias e BORGES, Roxana Cardoso B. Op. Cit. p - 67.

${ }^{28}$ SILVA, José Afonso. Op. Cit. p - 58.
}

(C) 2008. Departamento de Direito da UFSM. Todos os direitos reservados. 
bem elucida Luís Paulo Sirvinskas, "entende-se por qualidade do meio ambiente o estado do meio ambiente ecologicamente equilibrado que proporciona uma qualidade de vida digna para o ser humano. Essa qualidade de vida está relacionada com a atividade contínua e ininterrupta das funções essenciais do meio ambiente". ${ }^{29}$

Ocorre que a qualidade do meio ambiente, além de servir de referencial para a qualidade de vida, constitui-se em um referencial de controle do meio ambiente com relação às agressões sofridas.

Destaca-se que "a preocupação jurídica do ser humano com a qualidade de vida e a proteção do meio ambiente, como bem difuso, é tema recente. Pode-se dizer que estas questões só vieram alcançar interesse dos estados a partir da constatação da deterioração da qualidade ambiental e da limitabilidade do uso dos recursos naturais". ${ }^{30}$

A qualidade do meio ambiente que enseja a qualidade de vida é direito de todos, sendo que "o homem tem o direito fundamental à liberdade, à igualdade e ao desfrute de condições de vida adequada em um meio, cuja qualidade lhe permita levar uma vida digna e gozar de bem-estar, e tem a solene obrigação de proteger e melhorar esse meio para as gerações presentes e futuras". ${ }^{31}$

Interessante evidenciar que para haver qualidade do meio ambiente é necessário a efetiva proteção do bem ambiental, o qual destaca Gomes Canotilho,

Em primeiro lugar, o bem ambiental pode qualificar-se como bem jurídico, se e na medida em que é objeto de uma disciplina autônoma distinta relativamente ao regime jurídico patrimonial dos bens, privados ou públicos, ou da 'res communes omnium' que o constituem. Conseqüentemente, é necessário que a proteção do ambiente tenha na lei ou em outras fontes um título jurídico autônomo. O fundamento da tutela específica e autônoma reconduzir-se-á, logicamente, à necessidade da conservação ou gozo do bem ambiental por parte da coletividade ou do particular 'uti cives'," ${ }^{32}$

É nesta acepção que deve ocorrer a proteção ambiental, entendendo o bem ambiental como um macrobem, conforme dispõe a Constituição Federal "bem de uso comum do povo", significando "que o proprietário, seja ele público ou particular, não

\footnotetext{
${ }^{29}$ SIRVINSKAS, Luís Paulo. Op. Cit. p - 113.

${ }^{30}$ VARELLA, Marcelo Dias e BORGES, Roxana Cardoso B. Op. Cit. p - 52.

${ }^{31}$ VARELLA, Marcelo Dias e BORGES, Roxana Cardoso B. Op. Cit. p - 64.

${ }^{32}$ CANOTILHO, Revista de legislação e Jurisprudência, n 3.800, p. 325-326.
}

(C) 2008. Departamento de Direito da UFSM. Todos os direitos reservados. 
poderá dispor da qualidade do meio ambiente ecologicamente equilibrado, devido à previsão constitucional, considerando-o macrobem de todos". 33

O conceito de qualidade de vida deve indicar as condições mínimas do meio físico, deve prever a obtenção de fatores necessários que conduzam ao atendimento das necessidades básicas, tais como alimentação, habitação, saúde e educação. As políticas que fornecem o instrumental necessário à aquisição desses bens não se opõem à política ambiental; ao contrário, elas se complementam. Não é possível uma boa qualidade de vida sem a devida política de proteção dos recursos naturais.

A qualidade do meio ambiente só existirá a partir da mudança do padrão e do conceito de desenvolvimento econômico, cujas atuais condições de vida são absolutamente inaceitáveis, pois no Brasil o desenvolvimento econômico sempre se fez de forma degradadora e poluidora pela falta de qualquer cuidado com a preservação dos recursos ambientais, mesmo percebendo-se a existência de vínculos bastante concretos entre a preservação ambiental e a atividade industrial.

Não só no Brasil, mas as demais nações industrializadas também estão envolvidas com problemas ambientais, tais como o crescimento desordenado de áreas ambientais urbanas e poluição industrial.

As abordagens para o desenvolvimento e para a melhoria do meio ambiente exigem reordenação das prioridades. As políticas de maximização de crescimento econômico, que não consideram suas conseqüências na sociedade e nos recursos disponíveis para a melhoria da qualidade de vida, precisam ser questionadas.

Antes que as mudanças de prioridades sejam atingidas, os indivíduos deverão ajustar suas próprias prioridades e assumir uma ética global individualizada, refletindo no seu comportamento o compromisso para a melhoria da qualidade do meio ambiente e da vida de todas as pessoas.

Dessa forma, pode-se afirmar que o Brasil está enfrentando um importante desafio quanto à introdução dos princípios do direito ambiental em seu ordenamento jurídico pela contrariedade dos mesmos aos interesses econômicos existentes.

Resta claro que a efetivação do princípio de proteção ao meio ambiente como princípio econômico implica, obrigatoriamente, a mudança de todo o padrão de acumulação de capital e a mudança do padrão e do conceito de desenvolvimento econômico.

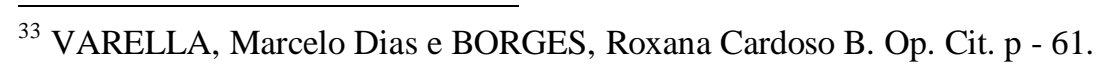


Assim, é na busca de tais modificações que tem-se visto o surgimento do movimento de massas que se organiza em escala planetária na defesa do meio ambiente e da qualidade de vida.

Dessa forma, "a compatibilização do desenvolvimento econômico-social com a preservação da qualidade do meio ambiente e do equilíbrio ecológico consiste na promoção do chamado desenvolvimento sustentável, que consiste na exploração equilibrada dos recursos naturais, nos limites da satisfação das necessidades e do bemestar da presente geração,assim como da sua conservação no interesse das gerações futuras". 34

\section{Desenvolvimento Sustentável}

A compreensão do desenvolvimento sustentável envolve alteração comportamental que não se restringe à formulação de conceitos a serem observados, mas que sobretudo impõem à formulação de políticas públicas necessárias à implementação do ecodesenvolvimento.

Importante destacar o entendimento de Élida Séguin e Francisco Carrera, "é mister suprir as necessidades essenciais do homem, a manutenção dos padrões básicos de consumo nos limites das possibilidades das nações em desenvolvimento, tão pouco privilegiadas e vítimas de um crescimento econômico globalizado e neoliberal, que, por vezes, ignora sua existência". 35

Ocorre que essa política de desenvolvimento tem que ser construída mediante a mudança da acepção social individual existente, determinando que cabe à sociedade civil resolver as questões ambientais, através da imposição de políticas públicas necessárias.

Neste viés descreveu Roberto P. Guimarães "que o desafio da sustentabilidade é um desafio eminentemente político (...), pois o argumento ecológico é, por definição, político". 36

Destaca-se que a ciência e a tecnologia melhoraram extraordinariamente a vida do homem, elevando os padrões de vida, facilitando o trabalho, combatendo doenças e criando novos produtos com grande incentivo ao consumo.

\footnotetext{
${ }^{34}$ Idem, ibidem. $\mathrm{p}-26-27$.

${ }^{35}$ SÉGUIN, Elida e CARRERA, Francisco. Op. Cit. p-119.

(C) 2008. Departamento de Direito da UFSM. Todos os direitos reservados. 
Ocorre que tais conquistas resultam em crescentes pressões sobre o nosso planeta, sem haver um beneficiamento de todos em escalas igualitárias, pois a maioria da população vive em estado de pobreza e luta para satisfazer suas necessidades básicas.

Importante considerar que a população mundial duplicou nos últimos cinqüenta anos e tende a dobrar neste século, o que implicará o maior esgotamento dos recursos naturais. E, sabe-se que quando as atividades econômicas destroem nossa base de recursos, o desenvolvimento como um todo é prejudicado.

Ocorre, entretanto, que sem o crescimento econômico não se tem como dirimir a pobreza, do que aumentam as pressões sobre o meio ambiente.

Neste contexto destaca Roberto Guimarães a necessidade de:

Um novo paradigma que situe o ser humano como o centro do processo de desenvolvimento deverá, necessariamente, considerar o crescimento econômico como um meio e não como um fim, terá que proteger as oportunidades de vida das gerações atuais e futuras, e terá, finalmente, que respeitar a integridade dos sistemas naturais que possibilitam a existência de vida na Terra. ${ }^{37}$

Nesta acepção observa-se que "a sustentabilidade vai mais além dos destinos da espécie humana: ela alcança a perpetuação da vida, e o valor intrínseco da criação ou do mundo natural". 38

Afirma-se, pois, que o modo viável de adequação do direito ambiental à uma política real e satisfatória de conservação dos recursos naturais, mediante o ajuste de práticas econômicas com uso equilibrado dos recursos naturais, adota a concepção de desenvolvimento sustentável, centrada na preocupação de garantir a manutenção das bases vitais da produção e reprodução do homem e de suas atividades garantindo igualmente ema relação satisfatória entre os homens e destes com o meio ambiente.

\section{CONSIDERAÇÕES FINAIS}

Para ocorrer a efetividade de um desenvolvimento sustentável é importante não só a existência de uma consciência ambiental, como ter clareza da abrangência do conceito de meio ambiente, tendo-se em mente que "os níveis de pobreza mundial e as

\footnotetext{
${ }^{36}$ VIOLA, Eduardo e FERREIRA, Leila da Costa (orgs.). Incertezas de Sustentabilidade na Globalização. São Paulo: Ed. Unicamp, 1996. p - 43

${ }^{37}$ VIOLA, Eduardo e FERREIRA, Leila da Costa (orgs.)..Op. Cit. p - 18.

(C) 2008. Departamento de Direito da UFSM. Todos os direitos reservados. 
relações humanas, em conjunto com as condições ambientais, passaram a integrar o cenário das preocupações com as gerações futuras do planeta". 39

Dessa forma, "espera-se que esta nova mentalidade resulte numa política clara e abrangente, que envolva a atuação conjunta de governo, empresários e comunidade, com o intuito de coibir as agressões inconseqüentes e continuadas ao meio ambiente". ${ }^{40}$

Evidencia-se que é mediante a ação conjunta da comunidade de forma a colocar em prática cotidiana atuações adquiridas através da conscientização ambiental que se terá a utilização de um instrumento eficaz na preservação do meio ambiente, pois

A importância discursiva da questão ambiental traduziu-se numa legislação comparativamente avançada, porém os comportamentos individuais estão muito aquém da consciência ambiental preente no discurso, sendo muito poucas as pessoas que pautam conscientemente seu cotidiano pelos critérios da eficiência energética, reciclagem de materiais, redução do consumo suntuário e participação voluntária em tarefas comunitárias de limpeza ambiental. ${ }^{41}$

Importante enfoque é estabelecido pelo mestre Édis Milaré ao afirmar que, Compatibilizar meio ambiente e desenvolvimento significa considerar os problemas ambientais dentro de um processo contínuo de planejamento, atendendo-se adequadamente às exigências de ambos e observando-se as suas inter-relações particulares a cada contexto sociocultural, político, econômico e ecológico, dentro de uma dimensão tempo/espaço. ${ }^{42}$

$\mathrm{O}$ enfoque que deve nortear todas as diretrizes e políticas em matéria ambiental na busca da implementação do desenvolvimento sustentado envolve a percepção não só da necessidade de preservação do meio ambiente, mas sobretudo da perpetuação da vida, mediante a formulação de políticas públicas agregadoras.

\section{REFERÊNCIAS BIBLIOGRÁFICAS}

ANTUNES, Paulo de Bessa. Direito Ambiental. Rio de Janeiro: Lumen Juris, 2001.

\footnotetext{
${ }^{38}$ MILARÉ, Édis, Op. Cit. p - 43.

${ }^{39}$ SÉGUIN, Elida e CARRERA, Francisco. Op. Cit. p-119.

${ }^{40}$ MILARÉ, Édis, Op. Cit. p - 43.

${ }^{41}$ VIOLA, Eduardo J. e LEIS, Hector R. A evolução das políticas ambientais no Brasil, 1971-1991: do bissetorialismo preservacionista para o multissetorialismo orientado para o desenvolvimento sustentável. Campinas: Ed. Unicamp, 1995. P - 93.

${ }^{42}$ MILARÉ, Édis, Op. Cit. p - 42.
}

(C) 2008. Departamento de Direito da UFSM. Todos os direitos reservados. 
BOBBIO, Norberto. A era dos direitos. Rio de Janeiro: Campus, 1992.

CANOTILHO, Revista de legislação e Jurisprudência, $n^{\circ} 3.800$.

CAPRA, Fritjof. A Teia da Vida: uma nova compreensão científica dos sistemas vivos. São Paulo: Cultrix, 1996.

COIMBRA, José de Ávila Aguiar. O outro lado do meio ambiente. São Paulo: Cetesb, 1990.

MACHADO, Paulo Affonso Leme. Direito Ambiental Brasileiro. São Paulo: Malheiros, 2001.

MCCORMICK, John. Rumo ao Paraíso. A história do Movimento Ambientalista. Rio de Janeiro: Relume-Dumerá, 1992.

MILARÉ, Édis, Direito do Ambiente. São Paulo: Revista dos Tribunais, 2001.

SÉGUIN, Elida e CARRERA, Francisco. Planeta Terra Uma Abordagem de Direito Ambiental. Rio de Janeiro: Lumen Juris, 2001.

SILVA, José Afonso da. Direito Ambiental Constitucional. São Paulo: Malheiros, 2000. 2002.

SIRVINSKAS, Luís Paulo. Manual de Direito Ambiental. São Paulo: Saraiva,

VARELLA, Marcelo Dias e BORGES, Roxana Cardoso B. O Novo em Direito Ambiental. Belo Horizonte: Del Rey, 1998.

VIEIRA, Litszt. Cidadania e Globalização. Rio de Janeiro: Record, 1998.

VIOLA, Eduardo e FERREIRA, Leila da Costa (orgs.). Incertezas de Sustentabilidade na Globalização. São Paulo: Ed. Unicamp, 1996.

VIOLA, Eduardo J. e LEIS, Hector R. A evolução das políticas ambientais no Brasil, 1971-1991: do bissetorialismo preservacionista para o multissetorialismo orientado para o desenvolvimento sustentável. Campinas: Ed. Unicamp, 1995. 